\title{
Removal of Congo red dye from aqueous solutions by a low-cost adsorbent: activated carbon prepared from Aloe vera leaves shell
}

\author{
Yusef Omidi Khaniabadi ${ }^{1}$, Mohammad Javad Mohammadi ${ }^{2,3}$, Mojtaba Shegerd $^{4}$, Shahram Sadeghi ${ }^{5}$, Sedigheh Saeedi ${ }^{6}$, \\ Hassan Basiri ${ }^{78^{*}}$ \\ ${ }^{1} \mathrm{MSc}$ of Environmental Health, Health Care System of Karoon, Ahvaz Jundishapur University of Medical Sciences, Ahvaz, Iran \\ ${ }^{2} \mathrm{PhD}$, Abadan School of Medical Sciences, Abadan, Iran \\ ${ }^{3} \mathrm{PhD}$, Student Research Committee, Department of Environmental Health Engineering, School of Public Health and Environmental \\ Technologies Research Center, Ahvaz Jundishapur University of Medical Sciences, Ahvaz, Iran \\ ${ }^{4} \mathrm{BSc}$ of Occupational Health, Health Center of East, Ahvaz Jundishapur University of Medical Sciences, Ahvaz, Iran \\ ${ }^{5} \mathrm{MSc}$ of Environmental Health, Environmental Health Research Center, Kurdistan University of Medical Sciences, Sanandaj, Iran \\ ${ }^{6} \mathrm{MSc}$ of Environmental Health, Sama Technical and Vocatinal College, Islamic Azad University, Izeh Branch, Izah, Iran \\ ${ }^{7} \mathrm{MSc}$ of Environmental Health, Rural Water and Wastewater Company, Semnan, Iran \\ ${ }^{8} \mathrm{MSc}$ of Environmental Health, Department of Environmental Health Engineering, School of Health, Lorestan University of Medical \\ Sciences, Lorestan, Iran
}

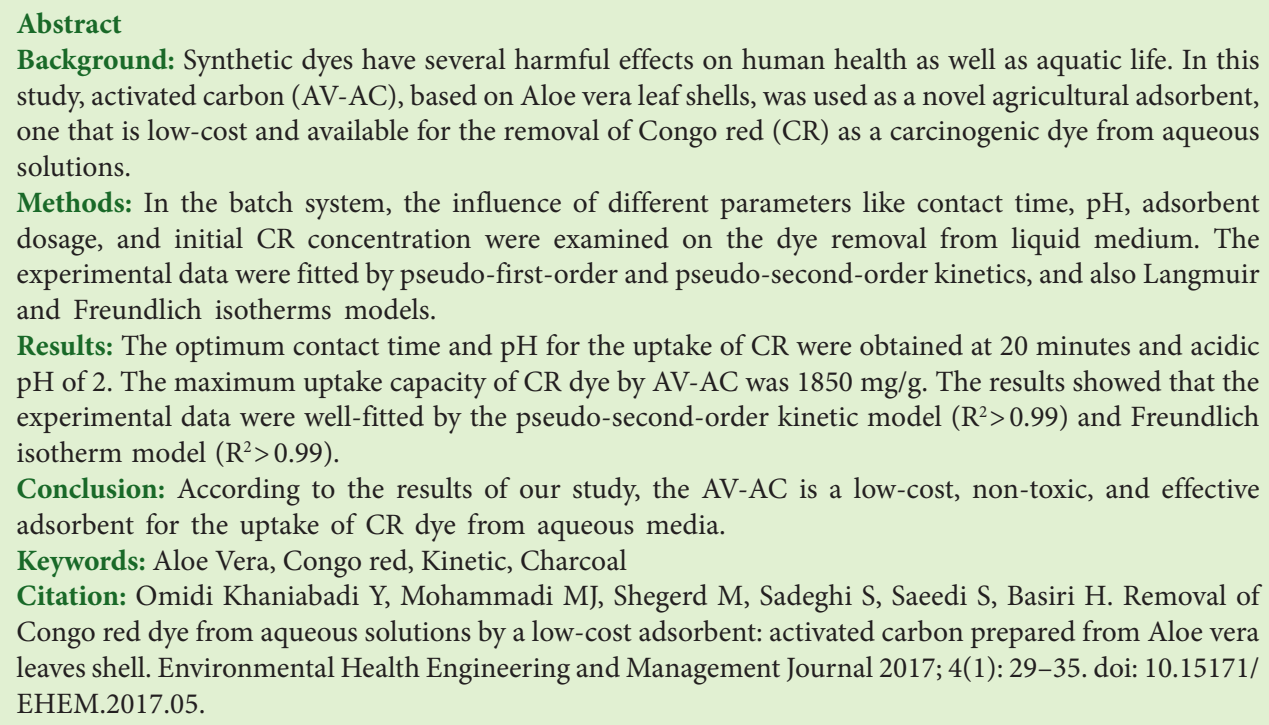

\section{Article History:}

Received: 25 August 2016

Accepted: 1 November 2016

ePublished: 28 November 2016

\section{Introduction}

Water pollution caused by discharge of wastewater as a result of industrial activities has been considered one of the grave environmental issues in the world, especially in developing countries (1-3). The discharge of many organic and inorganic pollutants into water media by different industries, as a global environmental problem, has stimulated worldwide attention because of their harmful effects on the environment and also human health $(4,5)$. One of the most important of these pollutants is dye substances. Various industries generate large volumes of dye containing effluents, such as the textiles, paper, rubber, leather, cosmetics, and food industries. The disposal of these coloured wastewaters without acceptable treatment into aquatic bodies will adversely influence the natural aquatic environment as well as have carcinogenic and mutagenic effects on human beings $(6,7)$. Thus, removal of these dyes is essential before these are discharged into the water bodies (8). Among different kinds of anionic dyes, Congo red (CR) (4-aminonaphthalene-1-sulphonic acid) is a benzidine-based anionic diazo dye, which is generated by some industries, including textiles, printing and dyeing, paper, rubber and plastic industries. It is toxic for many organisms and is a doubted carcinogen and mutagen dye (6). CR is very stable to biological degradation; it has a complex aromatic structure $(5,9,10)$. Several physical, chemical and microbial methods, including membrane separation, ion exchange, biological 
degradation, coagulation-flocculation, electrochemical techniques, chemical oxidation, and adsorption, have been used to remove CR from coloured water $(11,12)$. Among these processes, the adsorption technique is current due to its simplicity, high sorption capacity, environmental friendliness, non-toxicity, and availability of a wide range of sorbents. Adsorption onto activated carbon because of its high surface area and high uptake capacity has been commonly used as an adsorbent for the remove of organic pollutants, but it is high-priced, and is hard to regenerate $(2,13)$. In addition to activated carbon, some adsorbentssuch as montmorillonite (14), rice husk (15), bentonite (16), rice hull ash (17), Azadirachta indica leaf (18), Jujuba seeds (19), red mud (20), polypyrrole-polyaniline nanofibres (21), anion exchange membrane (22), and ball-milled sugarcane bagasse (23) - have been employed for the removal of CR dye. Today, more attention is being given to the use of low-cost adsorbents. Aloe vera grows in warm tropical areas such as the United States, Africa, Australia, South America, India and Iran (2). The original material of Aloe vera is used in the production of latex substance and drugs, but the Aloe vera leaves shell are by-products of the agricultural industries $(2,3,24)$. Omidi-Khaniabadi et al used the Aloe vera leaf wastes as a novel adsorbent for the adsorption of pollutants such as 4-chlorophenol (2), methylene blue (24), aniline and methyl orange (6) from aqueous solutions. In all the abovementioned contaminants, the results obtained were of interest for their removal. In this study, Aloe vera leaves shells were used as a cheap adsorbent to produce the activated carbon for CR dye uptake from synthetic wastewater.

\section{Materials and Methods}

Materials

Aloe vera leaves were collected from suburban farms of Ahvaz city in Khuzestan province, Iran. The chemical substances-which included CR dye, $\mathrm{H}_{2} \mathrm{SO}_{4}$ and $\mathrm{NaOH}-$ were acquired from Merck Co, Germany. The molecular structure of CR dye is presented in Figure 1. Dye stock solution $(1000 \mathrm{mg} / \mathrm{L})$ was prepared by dissolving $1 \mathrm{~g}$ of CR dye in $1 \mathrm{~L}$ deionized water and different concentrations were made by dilution of the stock solution. A rotary shaker (Behdad-Rotomix model) was used to mix the suspension of dye and AV-AC at $150 \mathrm{rpm}$.

\section{Preparation of adsorbent}

All the waste was carefully washed by deionized water to eliminate the pollutants and impurities. It was then dried in an oven at $105^{\circ} \mathrm{C}$ for 24 hours. The dried shells

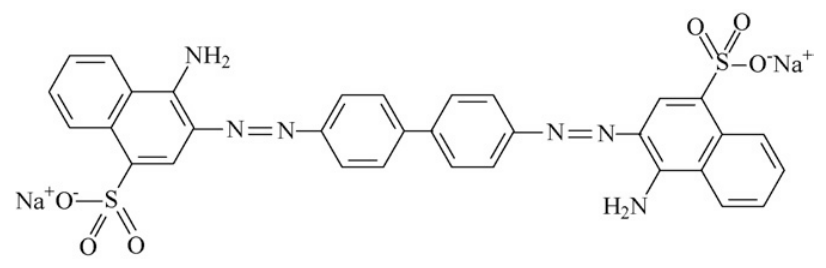

Figure 1. Molecular structure of Congo red (CR). were crushed through a laboratory mill and were then sieved. The particle sizes with a range of 300-500 $\mu \mathrm{m}$ were carbonized in a furnace at $550^{\circ} \mathrm{C}$ for 20 minutes in a without-air condition and prepared activated carbon was again crushed and sieved (mesh no $=40$ ) for the uptake experiments.

\section{Characterization and analysis}

For elemental analysis of AV-AC samples, a Heraeus Elemental Analyser (Jobin-Yvon Ultima ICP-AES) was used. The surface morphology of the adsorbent was characterized (before and after CR uptake) by a scanning electron microscope (SEM, Jeol Model Jsm-T330). The remaining concentration of $\mathrm{CR}$ in the solution was measured through an UV-Vis spectrophotometer (PG Instrument Limited Model) at a maximum absorbance wavelength of $495 \mathrm{~nm}(\lambda \max )$.

Zero point of charge ( $\mathrm{pHzpc}$ ) of the adsorbent was determined by preparing $50 \mathrm{~mL} 0.01 \mathrm{M} \mathrm{NaCl}$ solution in a $100 \mathrm{~mL}$ Erlenmeyer flask. The initial $\mathrm{pH}$ in each flask was adjusted in the range of 2 to 12 by $0.1 \mathrm{~N} \mathrm{H}_{2} \mathrm{SO}_{4}$ or $\mathrm{NaOH}$ solutions. In each flask containing $\mathrm{NaCl}$ solution, $0.1 \mathrm{~g}$ of sorbent was poured, and then the suspensions were mixed for 24 hours by a rotary shaker. After mixing stage, the final $\mathrm{pH}$ of solutions was determined to identify $\mathrm{pHzpc}$.

\section{Adsorption experiments}

The batch adsorption experiments were conducted to identify the effects of various factors including contact time (0-100 minutes), $\mathrm{pH}(2-12)$, adsorbent dosage $(0.5-5 \mathrm{~g} / \mathrm{L})$, and adsorbate content $(100-500 \mathrm{mg} / \mathrm{L})$ on the sorption of CR by using AV-AC. In all, 44 samples were taken, and the results analysed and the figures drawn in Excel software. All the experiments were performed at laboratory temperature $\left(25^{\circ} \mathrm{C}\right)$ and were then shacked at $150 \mathrm{rpm}$ in a $250 \mathrm{~mL}$ Erlenmeyer flask. After agitation time, the suspension was filtered through a fibreglass paper $(0.45 \mu \mathrm{m})$ and the absorbance of the clear sample was analysed to determine the remaining CR. The amounts of $\mathrm{CR}$ adsorbed on AC-AV and the sorption percentage (\%) were computed by the following equations:

$$
q_{e}=\frac{\left(C_{0}-C_{e}\right) \mathrm{V}}{m}
$$

$$
\operatorname{Sorption}(\%)=\frac{\left(C_{0}-C_{e}\right)}{C_{0}} \times 100
$$

where $q_{e}(\mathrm{mg} / \mathrm{g})$ is the uptake capacity the AV-AC. $C_{0}$ and $C_{e}$ are respectively the initial and equilibrium dye concentrations in the solution $(\mathrm{mg} / \mathrm{L}) . V$ and $m$ are respectively the volume of solution (L) and adsorbent mass (mg).

\section{Results}

Characterization

The elemental analysis of chemical composition of the $\mathrm{AV}$-AC illustrated that $\mathrm{Ca}, \mathrm{O}, \mathrm{K}$, and $\mathrm{Mg}$ are the majors that formed $92.7 \%$ of the weight (wt. \%) of the adsorbent. 
$\mathrm{Na}(5.92 \%)$ and $\mathrm{Cl}(1.35 \%)$ are the minors comprising the adsorbent $(2,3)$. Figure $2 \mathrm{~A}$ and $2 \mathrm{~B}$ respectively explain the morphology of the surface of activated carbon before and after the CR uptake.

\section{Effect of contact time}

The effects of different contact times on the sorption of CR dye by Aloe vera leaves shell-based activated carbon (AV$\mathrm{AC}$ ) at the time intervals of $0-100$ minutes in $100 \mathrm{~mL}$ dye solution and $1 \mathrm{~g} / \mathrm{L}$ of $\mathrm{AV}-\mathrm{AC}$ at the initial $\mathrm{pH}$ of solution were investigated. The results are shown in Figure 3A.

\section{Kinetics study}

The experimental data of CR dye by AV-AC was fitted by three adsorption kinetics, including pseudo-first-order, pseudo-second-order, and intraparticle diffusion models to obtain better understanding of the sorption process.

The pseudo-second-order kinetic model and parameters of the uptake of CR sorption by AV-AC are illustrated in Figure $3 \mathrm{~B}$ and Table 1 respectively. As can be seen in Table 1 , the highest correlation coefficient $\left(\mathrm{R}^{2}\right)$ of $\mathrm{CR}$ adsorption was related to the pseudo-second-order kinetic. Therefore, the adsorption process of $\mathrm{CR}$ dye by $\mathrm{AV}-\mathrm{AC}$ was followed by the pseudo-second-order kinetic model.

\section{Effect of solution $\mathrm{pH}$ and adsorbent dosage}

The effect of solution $\mathrm{pH}(2-12)$ on the uptake of CR (initial concentration $=100 \mathrm{mg} / \mathrm{L}$ ) by $\mathrm{AV}-\mathrm{AC}$ has been shown in Figure 4A. As is obvious, by increment the solution $\mathrm{pH}$, from 2 to 12 , the uptake capacity of the adsorbent was decreased. The maximum uptake of $\mathrm{CR}$ (100 mg/g) by AV-AC was obtained in pH 2. Thus, pH 2 has been selected as the optimum $\mathrm{pH}$ for the next stages. As seen in Figure 4A, the isoelectric point of the activated carbon from natural adsorbent was observed at $\mathrm{pH}$ of 11.3. There were positive charges on the AV-AC surface at the lower $\mathrm{pH}$ values of the isoelectric point, which will promote a reaction with $\mathrm{CR}$ as an azo dye.

The effect of different adsorbent dosages of $\mathrm{AV}$-AC in an initial $\mathrm{CR}$ concentration $(100 \mathrm{mg} / \mathrm{L})$ at $25^{\circ} \mathrm{C}$ was

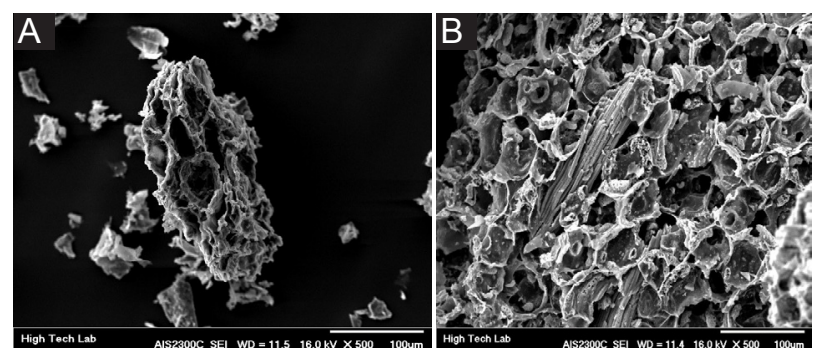

Figure 2. SEM image the AV-AC (A) before and (B) after the uptake process of Congo red (CR).
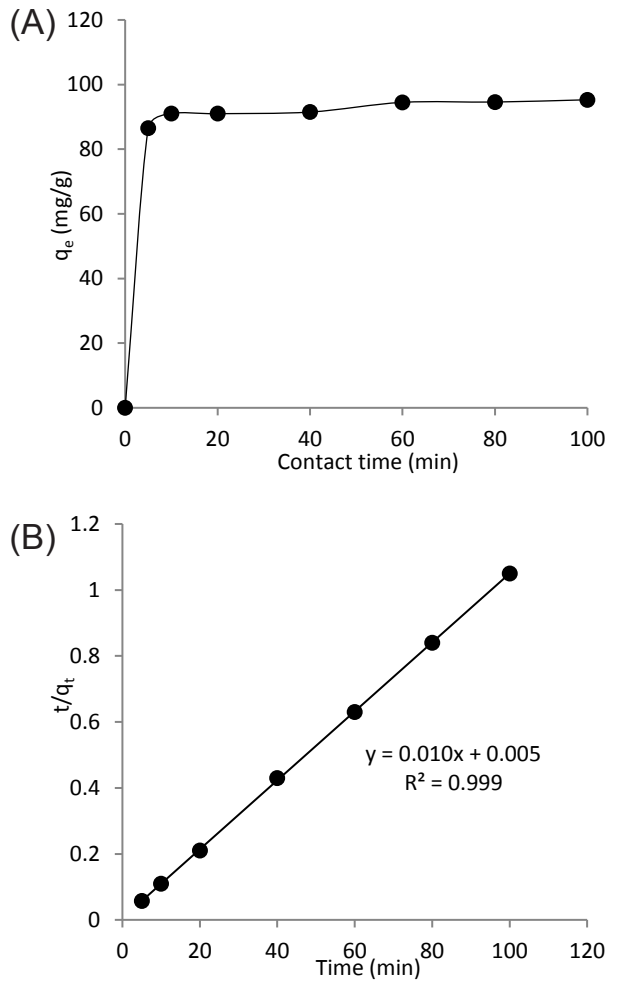

Figure 3. (A) The effect of contact time on the sorption of Congo red $(C R)$ dye by AV-AC (CR con. $=100 \mathrm{mg} / \mathrm{L}, \mathrm{pH}=7$ and adsorbent dosage $=1 \mathrm{~g} / \mathrm{L}$ ) and $(\mathrm{B})$ pseudo-second-order kinetic model.

examined. The results are explained in Figure 4B.

\section{Effect of initial dye concentration}

The influence of initial content (100 to $500 \mathrm{mg} / \mathrm{L}$ ) on the uptake capacity of $\mathrm{CR}$ by $\mathrm{AV}-\mathrm{AC}$ was evaluated. As shown in Figure 5A, the adsorption value of $\mathrm{AV}-\mathrm{AC}$ at the beginning was quickly increased by the rise in $C R$ concentration in the dye solution.

\section{Isotherm study}

Two uptake isotherm models, including Langmuir and Freundlich, were applied to fit the experimental data of CR dye removal by AV-AC.

As can be seen in Figure 5B, the amount of $\mathrm{K}_{\mathrm{f}}$ and $n$ were obtained from the cut-off and gradient of liner plotting of $\ln \mathrm{q}_{\mathrm{e}} \mathrm{vs}$. $\ln \mathrm{C}_{\mathrm{e}}$ respectively. The uptake isotherm parameters of the Langmuir and Freundlich models are presented in Table 2. As is obvious, the value of the correlation coefficient $\left(\mathrm{R}^{2}\right)$ of the Langmuir $\left(\mathrm{R}^{2}>0.96\right)$ model was lower than Freundlich $\left(\mathrm{R}^{2}>0.99\right)$ isotherm model.

\section{Discussion}

As seen in Figure 2A, before the uptake of CR dye, the surface morphology of adsorbent had irregular cavities

Table 1. Calculated kinetic parameters of Congo red (CR) dye sorption onto AV-AC

\begin{tabular}{lccccccccc}
\hline \multirow{2}{*}{ Adsorbate } & \multicolumn{3}{c}{ Pseudo-first-order } & \multicolumn{3}{c}{ Pseudo-second-order } & \multicolumn{3}{c}{ Intraparticle diffusion } \\
\cline { 2 - 10 } & $\mathrm{q}_{\mathrm{e}}(\mathrm{mg} / \mathrm{g})$ & $\mathrm{K}_{1}(1 / \mathrm{min})$ & $\mathrm{R}^{2}$ & $\mathrm{q}_{\mathrm{e}}(\mathrm{mg} / \mathrm{g})$ & $\mathrm{K}_{2}(\mathrm{~g} / \mathrm{mg} \cdot \mathrm{min})$ & $\mathrm{R}^{2}$ & $\mathrm{C}(\mathrm{mg} / \mathrm{g})$ & $\mathrm{K}\left(\mathrm{mg} / \mathrm{g} \mathrm{min} \mathrm{min}^{1 / 2}\right)$ & $\mathrm{R}^{2}$ \\
\hline Congo red & 1.03 & $2 \times 10^{-4}$ & 0.84 & 100 & $2.4 \times 10^{-3}$ & 0.99 & 2.52 & $8 \times 10^{-2}$ & 0.97 \\
\hline
\end{tabular}


(A)

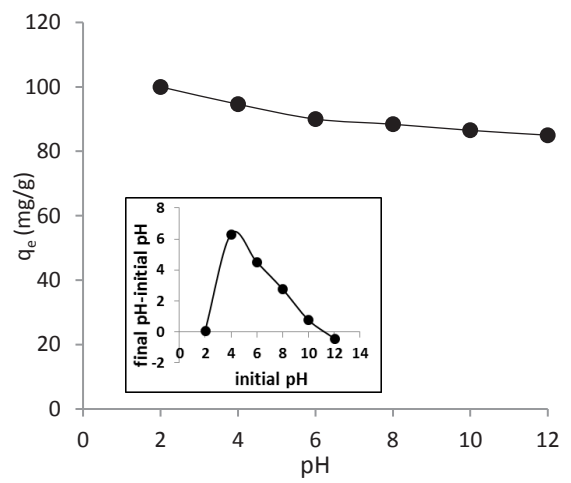

(B)

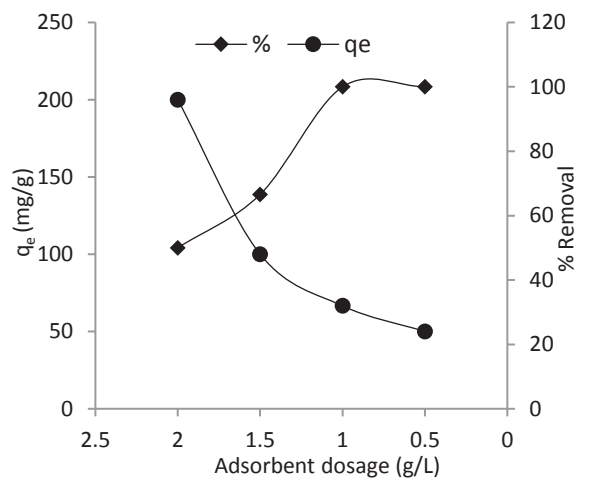

Figure 4. (A) The effect of $\mathrm{pH}$ on the uptake of $\mathrm{CR}$ dye by AV-AC (contact time $=20 \mathrm{~min}, \mathrm{CR}$ solution con. $=100 \mathrm{mg} / \mathrm{L}$ and activated carbon dosage $=1 \mathrm{~g} / \mathrm{L}$ ) and $(\mathrm{B})$ the effect of adsorbent dosage on the sorption (contact time $=20 \mathrm{~min}$, CR solution con. $=100 \mathrm{mg} / \mathrm{L}$ and $\mathrm{pH}=2$ ).

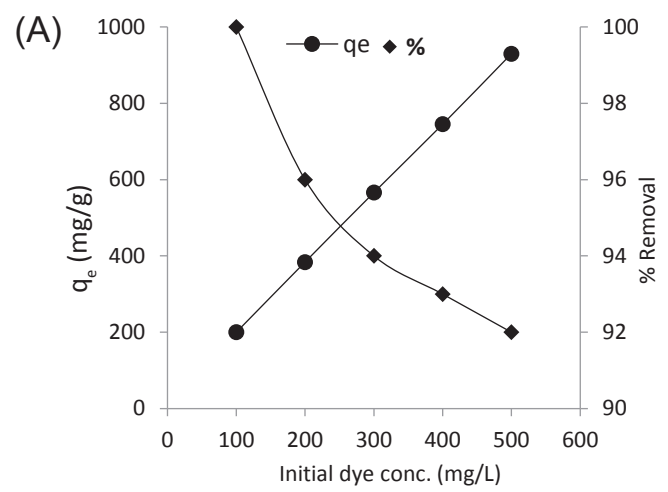

(B)

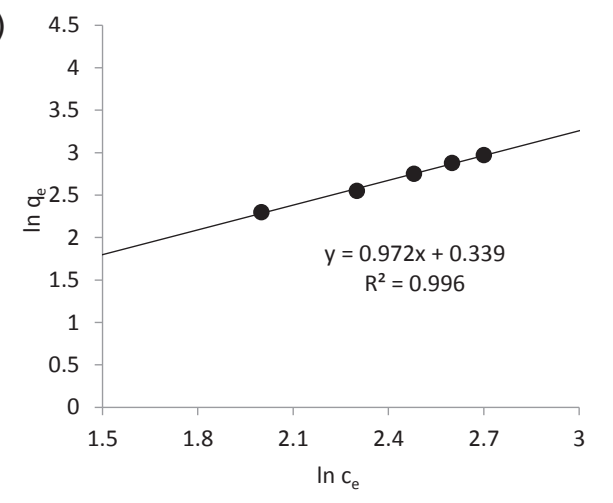

Figure 5. (A) The effect of initial concentration on the sorption of $\mathrm{CR}$ dye by AV-AC (contact time $=20 \mathrm{~min}, \mathrm{pH}=2$ and activated carbon dosage $=0.5 \mathrm{~g} / \mathrm{L}$ ) and $(\mathrm{B})$ Freundlich isotherm model. via fine open holes. After adsorption, as can be seen in Figure 2B, a smoother configuration, regular surface, and expanded pores were formed, after the uptake of adsorbate onto activated carbon (3). The expansion of the pores can be because of the uptake of CR onto the sorbent surface that filled these pores.

The contact time of the uptake process is an important parameter in the context of the economic aspects of the treatment of polluted water (3). The plot of contact time illustrates that the sorption of CR dye was rapidly increased at the first of the uptake process due to the availability of more vacant sites at the adsorbent surface and, with increases in contact time, these vacant sites were filled by CR. Thus, adsorption capacity was gradually increased. The equilibrium was acquired at contact time of 20 minutes $\left(q_{c}=91 \mathrm{mg} / \mathrm{g}\right)$ and then slowly reached a fixed state during the residual time up to 100 minutes. Thus, the contact time of 20 minutes was chosen as the optimum for the subsequent stages.

Table 3 illustrates the uptake capacity and equilibrium time of CR uptake by various adsorbents. As can be seen, the comparison of low-cost adsorbent (AV-AC) with other sorbents of CR illustrates that this adsorbent has a high uptake capacity $(91.0 \mathrm{mg} / \mathrm{g})$ and its sorption is approximately 3 to 5 times higher than that of chitosan $(19.15 \mathrm{mg} / \mathrm{g})$, valoria bryopsis $(10.52 \mathrm{mg} / \mathrm{g})$, and pinus brutia $(35.3 \mathrm{mg} / \mathrm{g})$, obtained from other studies. This may be due to the unique characteristics of AV-AC (2).

The pseudo-first-order kinetic is expressed by Eq. (3):

$\ln \left(q_{e}-q_{t}\right)=\ln q_{e}-K_{1} t$

where $q_{e}(\mathrm{mg} / \mathrm{g})$ and $q_{t}(\mathrm{mg} / \mathrm{g})$ are respectively the amounts of $\mathrm{CR}$ dye adsorbed onto the AV-AC surface at the equilibrium and at $t(\mathrm{~min})$. The parameters of $K_{1}$ (uptake rate constant, $1 / \mathrm{min}$ ) and $q_{e}$ were determined from linear plotting of $\ln \left(q_{e}-q_{t}\right)$ against $t(\mathrm{~min})$, which were acquired from the gradient and cut-off of the plot respectively (2). The experimental data of the CR adsorption were also analysed by the pseudo-second-order kinetic. This sorption model can be expressed by the Eq. (4):

$\frac{t}{q_{t}}=\frac{1}{k_{2} q_{e}^{2}}+\frac{t}{q_{e}}$

where $q_{e}$ and $q_{t}$ have similar definitions to the parameters of pseudo-first-order kinetic mentioned above. Kinetic rate constant $\left(\mathrm{K}_{2}, \mathrm{~g} / \mathrm{mg}\right.$. min) and adsorption capacity at equilibrium state $\left(\mathrm{q}_{\mathrm{e}}, \mathrm{mg} / \mathrm{g}\right)$ were obtained from the intercept and slope of $\mathrm{t} / \mathrm{q}_{\mathrm{t}}$ against $t(\mathrm{~min})$ respectively. The intraparticle diffusion model is explained by Eq. (5):

$q_{t}=k_{i d} \sqrt{t}+C$

where $K_{i d}\left(\mathrm{~g} / \mathrm{mg} \cdot \mathrm{min}^{1 / 2}\right)$ is the kinetic model constant rate and $\mathrm{C}(\mathrm{mg} / \mathrm{g})$ is associated with the thickness of the boundary layer. The amounts of $\mathrm{C}$ and $K_{i d}$ are achieved from the intercept and slope of the liner plot of $q_{t}$ versus $\sqrt{t}$ respectively.

Cheng et al illustrated the pseudo-second-order kinetic well followed the uptake of CR dye via activated carbon/ 
Table 2. Calculated isotherm parameters of Congo red (CR) dye sorption onto AV-AC

\begin{tabular}{lllllll}
\hline \multirow{2}{*}{ Adsorbate } & \multicolumn{2}{l}{ Langmuir } & \multicolumn{3}{l}{ Freundlich } \\
\cline { 2 - 7 } & $\mathbf{Q}_{\mathbf{m}}(\mathbf{m g} / \mathbf{g})$ & $\mathbf{b}(\mathrm{L} / \mathbf{m g})$ & $\mathbf{R}^{2}$ & $\mathbf{K}_{\mathbf{f}}$ & $\mathbf{n}$ & $\mathbf{R}^{2}$ \\
\hline Congo red & 1850 & $8.5 \times 10^{-4}$ & 0.96 & $4.6 \times 10^{-2}$ & 1.02 & 0.99 \\
\hline
\end{tabular}

Table 3. Comparison of various adsorbents in respect of sorption of Congo red (CR) dye from aqueous media

\begin{tabular}{|c|c|c|c|c|}
\hline Adsorbent & $C_{0}(\mathrm{mg} / \mathrm{L})$ & Equilibrium time (min) & $q_{e}(\mathrm{mg} / \mathrm{g})$ & Ref. \\
\hline EBTAC & 50 & $22 \mathrm{~h}$ & 21.73 & $(22)$ \\
\hline CB-CTAB & 20 & $4 \mathrm{~h}$ & 19.15 & $(25)$ \\
\hline Valoria bryopsis & 30 & 180 & 10.52 & (26) \\
\hline Pinus brutia & 100 & 120 & 35.3 & $(27)$ \\
\hline Maghemite nanoparticles & 20 & 30 & 20.0 & (28) \\
\hline Eichhornia crassipes & 104.45 & 90 & 4.97 & (29) \\
\hline PPy-PANI NFs & 50 & 120 & 50.50 & (30) \\
\hline AV-AC & 100 & 20 & 91.0 & This study \\
\hline
\end{tabular}

surfactant than other kinetics (5). In addition, according to the amount of $\mathrm{C}(\mathrm{mg} / \mathrm{g})$ for the uptake of $\mathrm{CR}$, the liner plot of this kinetic model did not pass through the origin. Thus, the intraparticle diffusion model is not the step of rate limiting in the adsorption of CR dye by AV-AC.

The solution $\mathrm{pH}$ changes the surface properties of the adsorbent and the level of adsorbate ionization $(2,3)$. Furthermore, the uptake of adsorbate is affected by the solution $\mathrm{pH}$ due to the sorption of $\mathrm{H}^{+}$and $\mathrm{OH}^{-}$ions in the liquid $(10,25)$. This outcome can be due to the change in the surface charge of the activated carbon. The amounts of positive charges onto the adsorbent surface were enhanced through decrease in initial solution $\mathrm{pH}$, subsequently causing increase in the sorption capacity in more acidic solution $\mathrm{pH}$. The electrostatic repulsions between the negatively charged $\mathrm{AV}-\mathrm{AC}$ and anionic dye of $\mathrm{CR}$ were increased in the basic $\mathrm{pH}$.

It was identified that with the increase in the AV-AC dosage from 0.5 to $2 \mathrm{~g} / \mathrm{L}$, the adsorption capacity was reduced from 200 to $50 \mathrm{mg} / \mathrm{g}$. Decrease in the sorption amounts of upper dosages may be due to the inaccessibility of the dye molecules that cannot cover all the surface sites of the adsorbent. In other words, a huge number of the active sites on the AV-AC surface cannot attain saturation state at higher dosages of the activated carbon. So, dose of $0.5 \mathrm{~g} / \mathrm{L}$ of AV-AC was chosen as the optimum dose for the subsequent stages of the sorption process.

The quantity of CR adsorbed was incremented from 200 to $929.88 \mathrm{mg} / \mathrm{g}$ by the increase in the adsorbate content from 100 to $500 \mathrm{mg} / \mathrm{L}$. This finding can be due to the fact that the adsorbed polluted created van der Waal's driving force to overcome the mass transmission resistance of CR dye to the active surface sites of the AV-AC. Thus, the above-mentioned power increase through an increase in the adsorbate content, therefore, caused an enhancement of CR sorption capacity.

Adsorption isotherms provide helpful requirements to identify the uptake mechanism and characteristics of the sorbent surface for the design of sorption systems $(26,27)$. The Langmuir model assumes that the monolayer uptake occurred onto the homogeneous surface of the AV-AC. This model is widely used to the uptake of pollutants from aqueous media. The Langmuir isotherm model is exhibited by Eq. (6):

$$
\frac{C_{e}}{q_{e}}=\frac{C_{e}}{Q_{m}}+\frac{1}{b Q_{m}}
$$

where $q_{e}(\mathrm{mg} / \mathrm{g})$ and $C_{e}(\mathrm{mg} / \mathrm{L})$ are the uptake capacity of the adsorbent and initial CR concentration at equilibrium time respectively. The values of $Q_{m}(\mathrm{mg} / \mathrm{g}$, the maximum uptake capacity of monolayer sorbent) and $b(\mathrm{~L} / \mathrm{mg}$, constant rate of Langmuir model) were obtained from the gradient and cut-off of liner plotting of $C_{e} / q_{e}$ versus $C_{e}$ respectively. The Freundlich isotherm model is generally used for multilayer adsorption on heterogeneous surface of the adsorbent. This uptake model can be illustrated by the following equation:

$$
\ln q_{e}=\ln k_{f}+\frac{1}{n} \ln C_{e}
$$

where $K_{f}(\mathrm{~L} / \mathrm{g})$ and $\mathrm{n}$ are the constant rates of isotherm model respectively associated with the uptake capacity and adsorption intensity.

It can be found that the experimental data of CR dye onto $\mathrm{AV}-\mathrm{AC}$ were well-fitted to the Freundlich isotherm model. In general, the adsorption bonds between activated carbon and adsorbed CR dye were suitably powerful, since the $n$ value achieved from the Freundlich model was further than that one. Rouf et al showed that the experimental data of CR dye by chitosan were well followed through the Freundlich isotherm model (28).

\section{Comparison with other studies}

The amount of maximum monolayer uptake capacity of CR dye by AV-AC was obtained at $1850 \mathrm{mg} / \mathrm{g}$. This amount has been compared with $\mathrm{Q}_{\mathrm{m}}$ achieved from the other studies for the removal of CR. Table 4 shows the maximum uptake capacity from the Langmuir model by various sorbents. It can be noted that the maximum of CR uptake capacity of the AV-AC is noticeably further than 
Table 4. Comparison of the maximum uptake capacity of AV-AC with that of other adsorbents

\begin{tabular}{lcc}
\hline Adsorbents & $\mathbf{Q}_{\mathrm{m}}(\mathrm{mg} / \mathrm{g})$ & Ref. \\
\hline Eichhornia crassipes & 1.58 & $(29)$ \\
Activated carbon (laboratory grade) & 1.88 & $(34)$ \\
Cashew nut shell & 5.18 & $(35)$ \\
Kaolin (clay materials) & 5.44 & $(36)$ \\
Activated carbon prepared from coir pith & 6.70 & $(37)$ \\
Acid activated red mud & 7.08 & $(20)$ \\
Bagasse fly ash & 11.89 & $(34)$ \\
Montmorillonite & 12.70 & $(14)$ \\
Cattail root & 38.79 & $(9)$ \\
Ball-milled sugarcane bagasse & 39.8 & $(23)$ \\
Neem leaf powder & 41.20 & $(38)$ \\
Magnetic core-manganese oxide shell & 42.0 & $(39)$ \\
Chitosan/montmorillonite nanocomposite & 54.52 & $(14)$ \\
Chitosan beads modified with CTAB & 94.39 & $(25)$ \\
Ca-bentonite & 107.41 & $(40)$ \\
Mesoporous activated carbon & 189.0 & $(41)$ \\
Maghemite nanoparticles & 208.33 & $(28)$ \\
Cone of Pinus brutia biomass & 329.6 & $(27)$ \\
CTAB modified chitosan beads & 352.2 & $(42)$ \\
AC/DDAC & 769.23 & $(5)$ \\
AV-AC & 1850 & This study \\
\hline
\end{tabular}

the maximum capacity of other sorbents.

\section{Conclusion}

In this study, CR was removed from aqueous media by Aloe vera leaf shells-based activated carbon (AV-AC). The influence of different parameters like contact time, $\mathrm{pH}$, adsorbent dosage, and CR content were evaluated on the uptake capacity of the adsorbent. The optimum uptake capacity of the AV-AC (91.0 mg/g) was achieved within 20 minutes at $\mathrm{pH}$ of 2 . The maximum monolayer adsorption capacity was obtained equal to $1850 \mathrm{mg} / \mathrm{g}$. The results showed that the experimental data were well-followed from the second-order-kinetic and Freundlich isotherm models. This natural adsorbent has several advantages, such as low cost, environmental friendliness, high uptake capacity, and non-toxicity. Thus, it can be considered an effective adsorbent on the removal of CR dye from aqueous solutions.

\section{Acknowledgments}

The authors wish to thank the Lorestan University of Medical Sciences.

\section{Ethical issues}

The authors certify that all data collected during the study are presented in this manuscript, and no data from the study has been or will be published separately.

\section{Competing interests}

The authors declare that they have no competing interests.

Authors' contributions

Study concept, design, and critical revision of the manuscript for important intellectual content: YOK; drafting of the manuscript and advisor, and performing experiments: YOK, HB, MJM, MS, ShS, and SeS.

\section{References}

1. Nourmoradi H, Nikaeen M, Khiadani (Hajian) M. Removal of benzene, toluene, ethylbenzene and xylene (BTEX) from aqueous solutions by montmorillonite modified with nonionic surfactant: Equilibrium, kinetic and thermodynamic study. Chem Eng J 2012; 191: 341-8. doi: 10.1016/j.cej.2012.03.029

2. Omidi-Khaniabadi Y, Jafari A, Nourmoradi H, Taheri F, Saeedi S. Adsorption of 4-chlorophenol from aqueous solution using activated carbon synthesized from aloe vera green wastes. J Adv Environ Health Res 2015; 3(2): 120-9.

3. Basiri H, Nourmoradi H, Moghadam FM, Moghadam KF, Mohammadian J, Khaniabadi YO. Removal of aniline as a health-toxic substance from polluted water by aloe vera waste-based activated carbon. Der Pharma Chemica 2015; 7(11): 149-55.

4. Jourvand M, Shams Khorramabadi G, Omidi-Khaniabadi Y, Godini H, Nourmoradi H. Removal of methylene blue from aqueous solutions using modified clay. J Bas Res Med Sci 2015; 2(1): 32-41.

5. Cheng Z, Zhang L, Guo X, Jiang X, Li T. Adsorption behavior of direct red 80 and Congo red onto activated carbon/surfactant: process optimization, kinetics and equilibrium. Spectrochim Acta A Mol Biomol Spectrosc 2015; 137: 1126-43. doi: 10.1016/j.saa.2014.08.138.

6. Omidi Khaniabadi Y, Heydari R, Nourmoradi H, Basiri H, Basiri H. Low-cost sorbent for the removal of aniline and methyl orange from liquid-phase: Aloe vera leaves wastes. Journal of the Taiwan Institute of Chemical Engineers 2016; 68: 90-98. doi: 10.1016/j.jtice.2016.09.025.

7. Omidi Y, Basiri H, Jafari A, Saeedi S, Goudarzi G, Taheri F, et al. Removal of textile dye methylene blue from liquid-phase by activated carbon from aloe vera wastes. Jundishapur J Health Sci 2016; In Press. doi: 10.17795/jjhs-38242.

8. Wasti A, Awan MA. Adsorption of textile dye onto modified immobilized activated alumina. Journal of the Association of Arab Universities for Basic and Applied Sciences 2016; 20: 26-31. doi: 10.1016/j.jaubas.2014.10.001.

9. Hu Z, Chen H, Ji F, Yuan S. Removal of Congo red from aqueous solution by cattail root. J Hazard Mater 2010; 173(1-3): 292-7. doi: 10.1016/j.jhazmat.2009.08.082.

10. Chatterjee S, Lee MW, Woo SH. Adsorption of Congo red by chitosan hydrogel beads impregnated with carbon nanotubes. Bioresour Technol 2010; 101(6): 1800-6. doi: 10.1016/j.biortech.2009.10.051.

11. Pavan FA, Dias SLP, Lima EC, Benvenutti EV. Removal of Congo red from aqueous solution by anilinepropylsilica xerogel. Dyes Pigm 2008; 76(1): 64-9. doi: 10.1016/j. dyepig.2006.08.027.

12. Khodadadi M, Saghi MH, Azadi NA, Sadeghi S. Adsorption of chromium VI from aqueous solutions onto nanoparticle sorbent: chitozan-Fe-Zr. J Mazandaran Univ Med Sci 2016; 26(141): 70-82.

13. Chen $\mathrm{H}$, Zhao J. Adsorption study for removal of Congo red anionic dye using organo-attapulgite. Adsorption 2009; 15(4): 381-9. doi: 10.1007/s10450-009-9155-Z.

14. Wang L, wang A. Adsorption characteristics of Congo red onto the chitosan/montmorillonite nanocomposite. J Hazard Mater 2007; 147(3): 979-85. doi: 10.1016/j. 
jhazmat.2007.01.145.

15. Han R, Ding D, Xu Y, Zou W, Wang Y, Li Y, et al. Use of rice husk for the adsorption of Congo red from aqueous solution in column mode. Bioresource Technology 2008; 99 (8): 2938-46. doi: 10.1016/j.biortech.2007.06.027.

16. Bulut E, Özacar MO, Şengil İA. Equilibrium and kinetic data and process design for adsorption of Congo Red onto bentonite. J Hazard Mater 2008; 154(1-3): 613-22.

17. Chou KS, Tsai JC, Lo CT. The adsorption of Congo red and vacuum pump oil by rice hull ash. Bioresour Technol 2001; 78(2): 217-9

18. Shankar S, Rai A, Ahmad A, Sastry M. Rapid synthesis of $\mathrm{Au}, \mathrm{Ag}$, and bimetallic Au core-Ag shell nanoparticles using Neem (Azadirachta indica) leaf broth. J Colloid Interface Sci 2004; 275(2): 496-502. doi: 10.1016/j.jcis.2004.03.003.

19. Reddy MC, Sivaramakrishna L, Reddy AV. The use of an agricultural waste material, Jujuba seeds for the removal of anionic dye (Congo red) from aqueous medium. J Hazard Mater 2012; 203-204: 118-27. doi: 10.1016/j. jhazmat.2011.11.083.

20. Tor A, Cengeloglu Y. Removal of Congo red from aqueous solution by adsorption onto acid activated red mud. J Hazard Mater 2006; 138(2): 409-15. doi: 10.1016/j. jhazmat.2006.04.063.

21. Bhaumik M, Maity A, Srinivasu V, Onyango M. Removal of hexavalent chromium from aqueous solution using polypyrrole-polyaniline nanofibers. Chem Eng J 2012; 181182: 323-33. doi: 10.1016/j.cej.2011.11.088.

22. Khan MA, Akhtar S, Zafar S, Shaheen A, Khan MA, Luque $\mathrm{R}$, et al. Removal of Congo red from aqueous solution by anion exchange membrane (EBTAC): adsorption kinetics and themodynamics. Materials 2015; 8(7): 4147-61. doi: $10.3390 / \mathrm{ma} 8074147$.

23. Zhang Z, Moghaddam L, O'Hara IM, Doherty WOS. Congo Red Adsorption by Ball-Milled Sugarcane Bagasse. Chem Eng J 2011; 178: 122-8. doi: 10.1016/j.cej.2011.10.024

24. Omidi-Khaniabadi Y, Jafari A, Basiri H, Saeedi S, Taheri F. A natural sorbent for the removal of textile dye methylene blue from liquid-phase: Aloe vera wastes. Int J Chem Environ Eng 2016; 7(1): 53-9.

25. Rouf S, Nagapadma M, Ramakoteswara Rao R. Removal of harmful textile dye Congo red from aqueous solution using chitosan and chitosan beads modified with CTAB. Int J Eng Res Appl 2015; 5(3): 75-82.

26. Jayaraj R, Jeyasingh Thanaraj P, Thillai Natarajan S, Martin Deva Prasath P. Removal of Congo red dye from aqueous solution using acid activated eco-friendly low cost carbon prepared from marine algae valoria bryopsis. J Chem Pharm Res 2011; 3(3): 389-96.

27. Bouguettoucha A, Chebli D, Mekhalef T, Noui A, Amrane A. The use of a forest waste biomass, cone of Pinus brutia for the removal of an anionic azo dye Congo red from aqueous medium. Desalination and Water Treatment. 2015; 55(7): 1956-65. doi: 10.1080/19443994.2014.928235.

28. Afkhami A, Moosavi R. Adsorptive removal of Congo red, a carcinogenic textile dye, from aqueous solutions by maghemite nanoparticles. J Hazard Mater 2010; 174(1-3): 398-403. doi: 10.1016/j.jhazmat.2009.09.066.

29. Wanyonyi WC, Onyari JM, Shiundu PM. Adsorption of Congo red dye from aqueous solutions using roots of Eichhornia crassipes: kinetic and equilibrium studies. Energy Procedia 2014; 50: 862-9. doi: 10.1016/j. egypro.2014.06.105.

30. Bhaumik M, McCrindle R, Maity A. Efficient removal of Congo red from aqueous solutions by adsorption onto interconnected polypyrrole-polyaniline nanofibres. Chem Eng J 2013; 228: 506-15. doi: 10.1016/j.cej.2013.05.026.

31. Du Q, Sun J, Li Y, Yang X, Wang X, Wang Z, et al. Highly enhanced adsorption of congo red onto graphene oxide/chitosan fibers by wet-chemical etching off silica nanoparticles. Chem Eng J 2014; 245: 99-106. doi: 10.1016/j. cej.2014.02.006.

32. Mohd Din AT, Hameed BH, Ahmad AL. Batch adsorption of phenol onto physiochemical-activated coconut shell. J Hazard Mater 2009; 161(2-3): 1522-9. doi: 10.1016/j. jhazmat.2008.05.009.

33. Omidi-Khaniabadi Y, Kamarehei B, Nourmoradi H, Goudarzi G, Jourvand M, Basiri $H$, et al. Hexadecyl trimethyl ammonium bromide-modified montmorillonite as a low-cost sorbent for the removal of methyl red from liquid-medium. IJE Transactions A: Basics 2016; 29(1):607. doi: 10.5829/idosi.ije.2016.29.01a.09.

34. Mall ID, Srivastava VC, Agarwal NK, Mishra IM. Removal of Congo red from aqueous solution by bagasse fly ash and activated carbon: kinetic study and equilibrium isotherm analyses. Chemosphere 2005; 61(4): 492-501. doi: 10.1016/j. chemosphere.2005.03.065.

35. Senthil Kumar P, Ramalingam S, Senthamarai C, Niranjanaa M, Vijayalakshmi P, Sivanesan S. Adsorption of dye from aqueous solution by cashew nut shell: studies on equilibrium isotherm, kinetics and thermodynamics of interactions. Desalination 2010; 261(1-2): 52-60. doi: 10.1016/j.desal.2010.05.032.

36. Vimonses V, Lei S, Jin B, Chow C, Saint C. Kinetic study and equilibrium isotherm analysis of Congo red adsorption by clay materials. Chem Eng J 2009; 148(2-3): 354-64. doi: 10.1016/j.cej.2008.09.009.

37. Namasivayam C, Kavitha D. Removal of Congo red from water by adsorption onto activated carbon prepared from coir pith, an agricultural solid waste. Dyes Pigm 2002; 54(1):47-58. doi: 10.1016/S0143-7208(02)00025-6.

38. Bhattacharrya KG, Sharma A. Azadirachta indica leaf powder as an effective biosorbent for dyes: a case study with aqueous Congo red solutions. J Environ Manage 2004; 71(3): 217-29. doi: 10.1016/j.jenvman.2004.03.002.

39. Zhai Y, Zhai J, Zhou M, Dong S. Ordered magnetic coremanganese oxide shell nanostructures and their application in water treatment. J Mater Chem 2009; 19: 7030-5. doi: 10.1039/B912767D.

40. Lian L, Guo L, Guo C. Adsorption of Congo red from aqueous solutions onto Ca-bentonite. J Hazard Mater 2009; 161(1): 126-31. doi: 10.1016/j.jhazmat.2008.03.063.

41. Lorenc-Grabowska E, Gryglewicz G. Adsorption characteristics of Congo red on coal based mesoporous activated carbon. Dyes Pigm 2007; 74(1):34-40. doi: 10.1016/j.dyepig.2006.01.027.

42. Jain R, Sikarwar S. Photocatalytic and adsorption studies on the removal of dye Congo red from wastewater. Int J Environ Pollut 2006; 27(1-3): 158-78. doi: 10.1504/ IJEP.2006.010460. 